Supporting Information

\title{
Pt and PtNi nanoparticle-supported multi-walled carbon nanotube electrocatalysts prepared by one-pot pyrolytic synthesis with an ionic liquid
}

Yu Yao, ${ }^{\dagger}$ Reiko Izumi,${ }^{\dagger}$ Tetsuya Tsuda,${ }^{*}{ }^{\dagger}$ Yoshifumi Oshima,${ }^{\dagger}$ Akihito Imanishi,${ }^{\S}$ Naoko Oda,${ }^{\S}$ and Susumu Kuwabata ${ }^{*} \dagger$

†Department of Applied Chemistry, Graduate School of Engineering, Osaka University, 2-1 Yamada-oka, Suita, Osaka 565-0871, Japan

\$School of Materials Science, Japan Advanced Institute of Science and Technology,

1-1 Asahidai, Nomi, Ishikawa 923-1292, Japan

$\S$ Department of Chemistry, Graduate School of Engineering Science, Osaka University,

1-3 Machikaneyama, Toyonaka, Osaka 560-8531, Japan

Corresponding Authors

*ttsuda@chem.eng.osaka-u.ac.jp

*kuwabata@chem.eng.osaka-u.ac.jp

Supporting Information Contents:

$\begin{array}{lc}\text { Figure S1 - S5 } & \text { p. S2 } \\ \text { Table S1 } & \text { p. S7 } \\ \text { Reference } & \text { p. S8 }\end{array}$



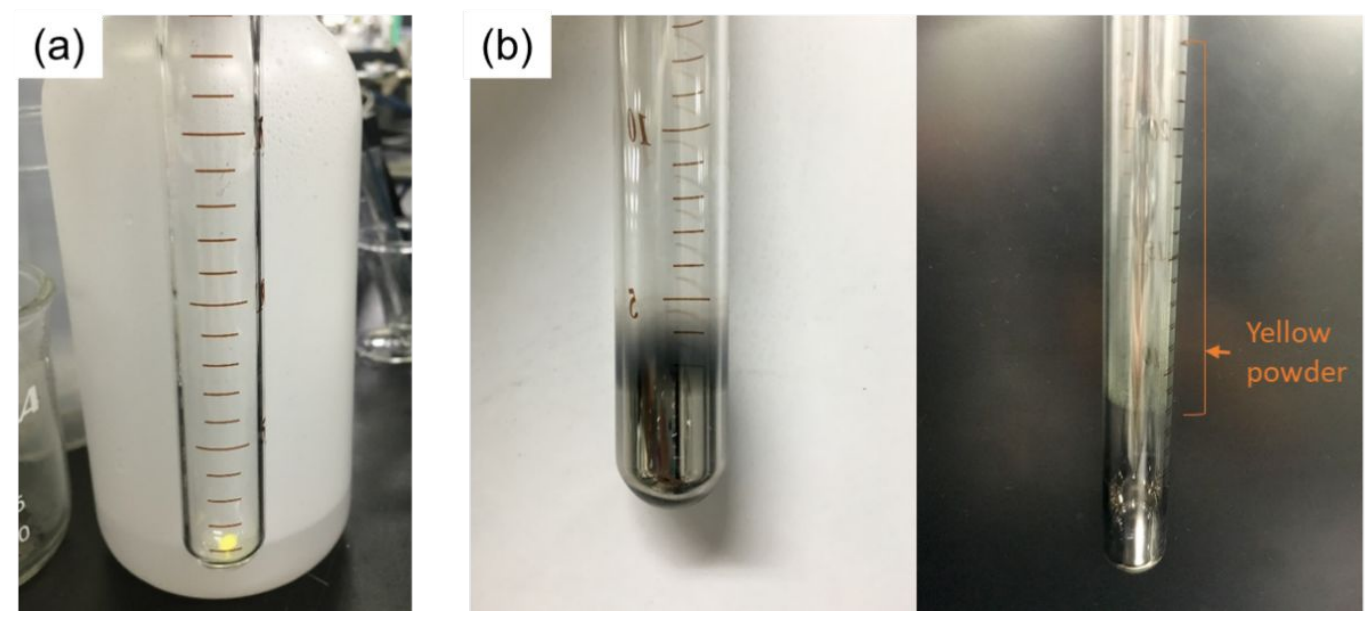

Figure S1. Photographs of a test tube containing $\mathrm{Pt}(\mathrm{acac})_{2}$ (a) before and (b) after heating. The test tube was heated at $10 \mathrm{~K} \mathrm{~min}^{-1}$ from room temperature to $473 \mathrm{~K}$. 

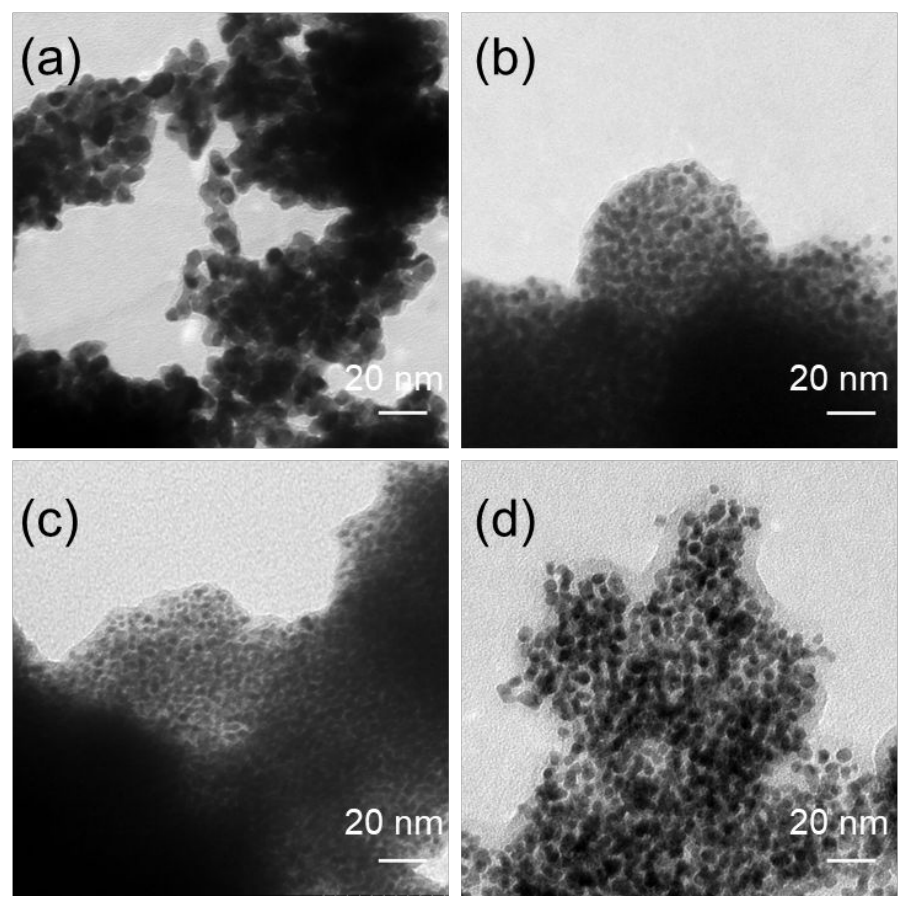

Figure S2. TEM images of Pt and PtNi nanoparticles prepared under the same conditions for specimens (a) 1, (b) 2, (c) 3 and (d) 4 but not containing MWCNTs. 

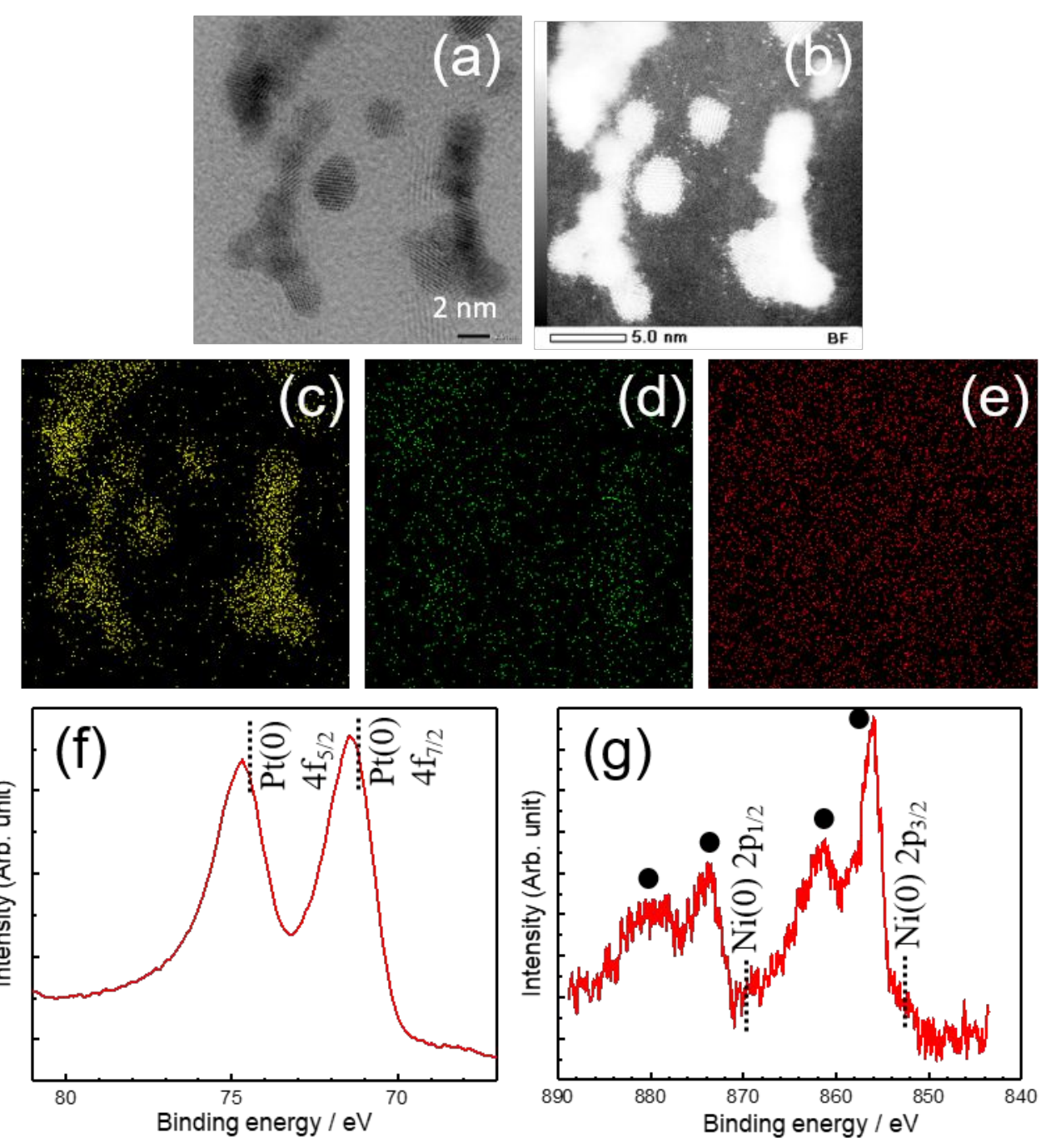

Figure S3. (a) High resolution TEM image, (b) HAADF-STEM image, (c-e) EDS mappings, and (f, g) XPS spectra of specimen 3. The elements are (c, f) Pt, (d, g) Ni, and (e) C. The characterization of XPS spectra was conducted using Ref. S1. The filled circles, •, shown in (g) are the XPS spectra related to $\mathrm{Ni}_{2} \mathrm{O}_{3}$. 

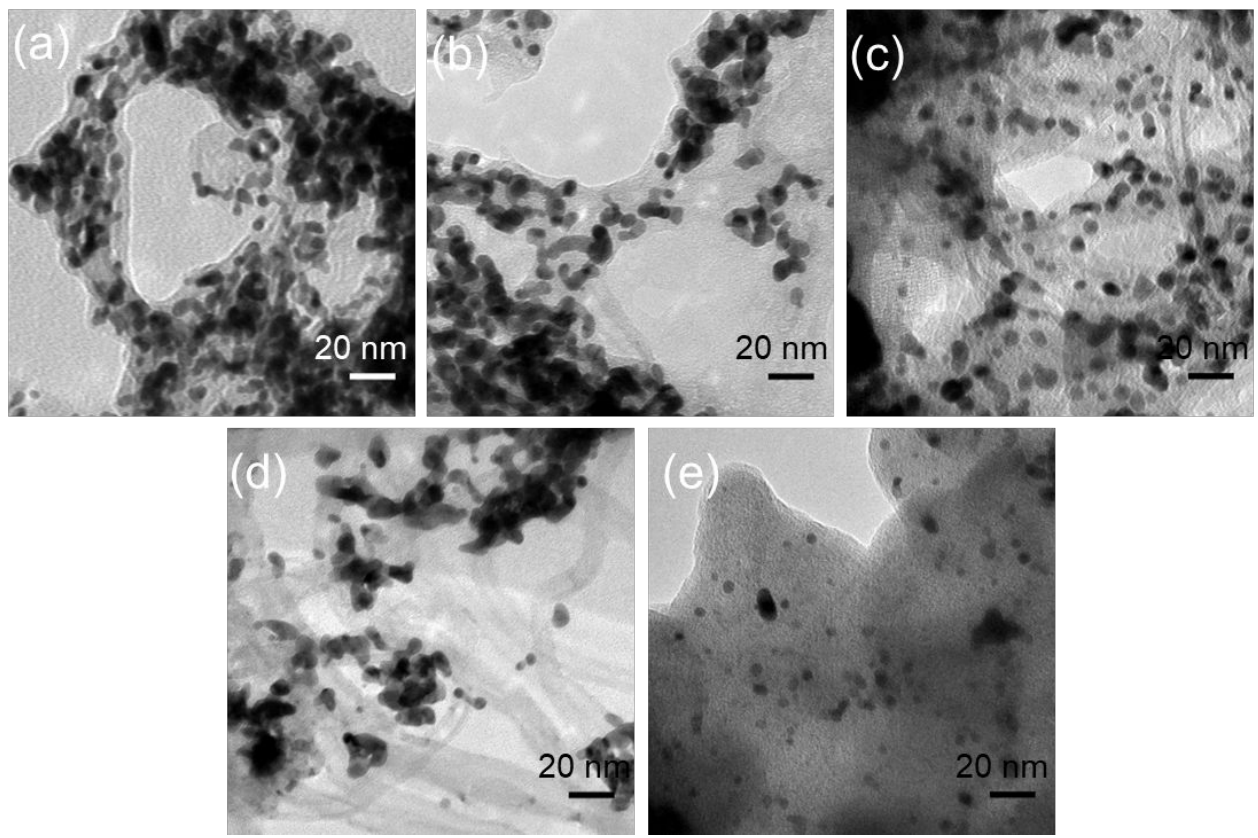

Figure S4. TEM images of specimens 1-5 after $15000^{\text {th }}$ potential cycle test. The specimens are (a) 1, (b) 2 , (c) 3, (d) 4, and (e) 5 . 

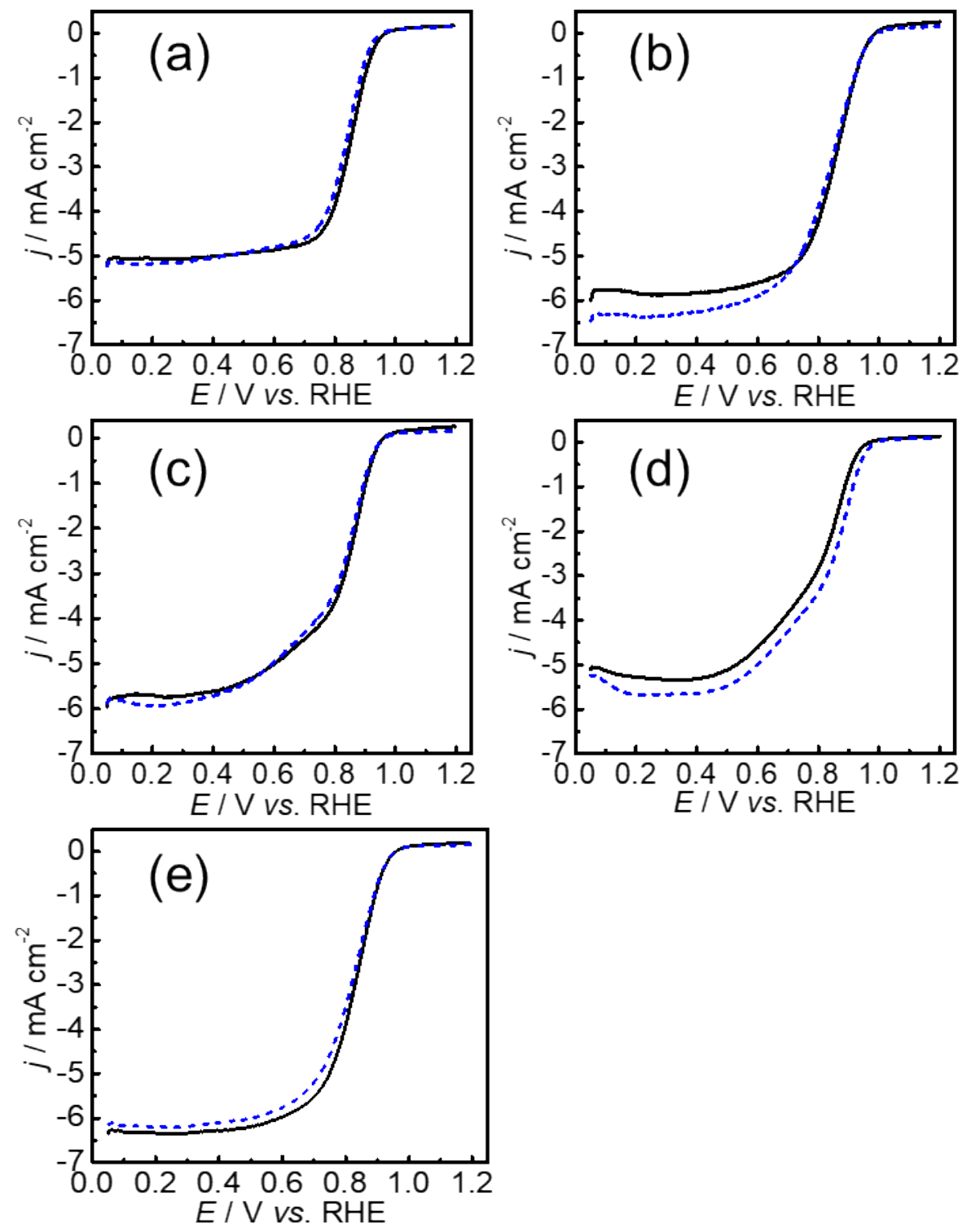

Figure S5. RDE-LSVs recorded at glassy carbon electrodes with the specimens in an $\mathrm{O}_{2}$-saturated $0.1 \mathrm{M} \mathrm{HClO}_{4}$ aqueous solution (-) before and (- - ) after the $15000^{\text {th }}$ potential cycle tests. The rotating speeds were $1600 \mathrm{rpm}$. The scan rates were $10 \mathrm{mV} \mathrm{s}^{-1}$. The specimens are (a) 1, (b) 2, (c) 3 , (d) 4, and (e) 5 . 
Table S1. Summary of Pt and PtNi alloy nanoparticles obtained by different pyrolytic conditions

\begin{tabular}{|c|c|c|c|c|c|c|c|c|}
\hline \multirow{2}{*}{\multicolumn{3}{|c|}{$\begin{array}{l}\text { Metal precursor concentration } \\
\qquad / \mathrm{mM}\end{array}$}} & \multirow[t]{3}{*}{$\begin{array}{l}\text { Agitation } \\
\text { time } / \mathrm{h}\end{array}$} & \multirow[t]{3}{*}{$\begin{array}{l}\text { Mean particle } \\
\text { size / nm }\end{array}$} & \multicolumn{4}{|c|}{$\begin{array}{c}\text { Composition of nanoparticle } \\
\text { / at } \%\end{array}$} \\
\hline & & & & & \multicolumn{2}{|c|}{$\begin{array}{c}\text { Without } \\
\text { MWCNTs }\end{array}$} & \multicolumn{2}{|c|}{$\begin{array}{c}\text { With } \\
\text { MWCNTs }^{c}\end{array}$} \\
\hline $\mathrm{Pt}(\mathrm{acac})_{2}$ & $\mathrm{Ni}\left[\mathrm{Tf}_{2} \mathrm{~N}\right]_{2}$ & $\mathrm{Ni}(\mathrm{acac})_{2}$ & & & $\mathrm{Pt}$ & $\mathrm{Ni}$ & $\mathrm{Pt}$ & $\mathrm{Ni}$ \\
\hline 5 & & - & 6 & $6.9(1.2)^{b}$ & 100 & - & 100 & - \\
\hline 15 & 5 & - & 4 & $4.0(0.7)^{b}$ & 91 & 9 & 89 & 11 \\
\hline 5 & 5 & - & 4 & $3.0(0.5)^{b}$ & 73 & 27 & 72 & 28 \\
\hline 5 & - & 5 & 4 & $4.9(0.9)^{b}$ & 38 & 62 & 42 & 58 \\
\hline
\end{tabular}

${ }^{a}$ The composition of the resulting nanoparticles was calculated from EDS measurement.

${ }^{b}$ The values in parentheses are standard deviations.

${ }^{c}$ These values show the composition of the specimens 1-4 determined from EDS measurement. 


\section{Reference}

(S1) Handbook of X-ray photoelectron spectroscopy; Chastain, J., King, Jr. R. C., Eds.; Physical Electronics, Inc., Minnesota, USA, 1995. 